\title{
Immunosuppressive treatment for myocarditis and borderline myocarditis in children with ventricular ectopic rhythm
}

\author{
Seshadri Balaji, Henry B Wiles, Mary Ann Sens, Paul C Gillette
}

\begin{abstract}
Objectives-To ascertain the responsiveness to immunosuppressive treatment of myocarditis and borderline myocarditis in children with ventricular ectopic rhythm (that is, all ventricular arrhythmia except benign premature ventricular contractions). To determine the impact of the diagnostic information provided by an endomyocardial biopsy specimen in these patients.

Background-The therapeutic value of performing an endomyocardial biopsy in children with ventricular ectopic rhythm is not established. In turn, the treatment of myocarditis with immunosuppressive drugs is also controversial.
\end{abstract}

Methods-The case notes and endomyocardial biopsy findings of all children with ventricular ectopic rhythm and a biopsy diagnosis of myocarditis were reviewed.

Results-Ten (14\%) of 69 patients with ventricular ectopic rhythm and an anatomically normal heart had histological evidence of myocarditis or borderline myocarditis. Eight patients received corticosteroids and efficacy was judged by regular 24 hour Holter monitoring. Total resolution of arrhythmia was seen in four, improvement in two, and no change in two patients. At follow up (8-39 months, mean 22 months), arrhythmia recurrence was seen in the two patients who showed an improvement but not resolution during treatment. Both received azathioprine with further reduction in ectopy rates. Patients who responded to treatment were symptomatic (six of six patients) at presentation compared with those who did not respond to treatment (none of two patients) who were not symptomatic. Five patients had a repeat biopsy specimen taken which confirmed histological improvement.

Conclusions-Steroid treatment seems to benefit a subset of children with ventricular ectopic rhythm and a biopsy diagnosis of myocarditis or borderline myocarditis. Because it can identify a treatable cause for the ventricular arrhythmia, endomyocardial biopsy is a valuable investigation in these patients.

(Br Heart f 1994;72:354-359)
Ventricular ectopic rhythm - that is, complex ventricular premature contractions, ventricular tachycardia, and ventricular fibrillation-is a rare but potentially serious problem in children. Most children with ventricular ectopic rhythm have congenital heart disease. Ventricular ectopic rhythm can, however, occur in children with no apparent structural heart disease. In a previous report we showed that such children may be found to have subclinical cardiomyopathy or unsuspected myocarditis when a endomyocardial biopsy sample is taken. ${ }^{1}$ This report considers children with ventricular ectopic rhythm and myocarditis or borderline myocarditis with particular reference to management with immunosuppressive drugs.

\section{Patients and methods}

PATIENTS

Between October 1987 and March 1993, 69 patients with ventricular ectopic rhythm and a structurally normal heart were referred for investigation. All had a non-invasive evaluation which consisted of an electrocardiogram, Holter 24 hour electrocardiogram, echocardiography, and a treadmill exercise test soon after presentation. This was followed by an invasive evaluation consisting of cardiac catheterisation, right ventricular angiography, an electrophysiological study (with programmed ventricular stimulation), and a right ventricular endomyocardial biopsy in all patients. Of the 69 patients studied, $10(14 \%)$ were found to have myocarditis or borderline myocarditis when the biopsy sample was examined and form the basis of this report.

Table 1 summarises the clinical details of these patients. The age of the patients ranged from 5 to 14.8 years, median 11 years. There were five boys and five girls. Symptoms were present in six and consisted of palpitations in two, chest pain in two, and syncope or near syncope in two. One patient had a history of supraventricular tachycardia, but is included here because he had inducible atrial and ventricular tachycardias during the electrophysiological study which prompted the biopsy. Another patient aged 8 years presented with ventricular tachycardia and was found to have coarctation of the aorta, but biopsy samples taken at catheterisation also showed myocarditis. A repeat biopsy sample taken three weeks after the operation for the coarctation continued to show myocarditis. $\mathrm{He}$ is 
Table 1 Patient characteristics and details of arrhythmia

\begin{tabular}{rllllll}
\hline Patient No. & Age (years) & Sex & Symptoms & ECG/Holter results & Exercise test results & EPS inducibility \\
\hline 1 & 5 & M & None & PVC & SD & NI† \\
2 & 6.5 & M & None & NS-VT & SD & NI \\
3 & 8 & F & URTI, lethargy & VT & VT & NI \\
4 & 8 & M & CoA, syncope & VT & NSD & VI, AFL, \\
5 & 10 & M & Chest pain & VT & AVRT \\
6 & 11 & M & Palpitations, near syncope & PVC & SD & NI \\
7 & 11.5 & F & None & VT & N & AFL, \\
8 & 11.7 & M & Palpitations, near syncope & SVT & NSD & VT, VF \\
9 & 12 & F & Chest pain & NS-VT & SD & VT \\
\hline
\end{tabular}

$\mathrm{AFL}=$ atrial flutter; AVNRT = atrioventricular; nodal reentry tachycardia; AVRT = atrioventricular reentry tachycardia; CoA $=$ coarctation; ECG = electrocardiogram; $\mathbf{N}=$ normal; $\mathrm{NI}=$ not induced; NS = nonsustained; $\mathrm{NSD}=$ not suppressed; $\mathrm{PVC}=$ premature ventricular contractions; $\mathrm{SD}=$ suppressed; SVT = supraventricular tachycardia; URTI $=$ upper respiratory tract infection; VF = ventricular fibrillation; VT = ventricular tachycardia.

$\star$ Reduced not abolished.

†Spontaneous NS-VT with isoproterenol.

included here as coarctation is not known to predispose to arrhythmia and because he was included in the previous report. ${ }^{1}$ The asymptomatic patients were referred when their heart rhythm abnormality was incidentally detected. Ventricular tachycardia was documented on a standard 12 lead electrocardiogram or Holter electrocardiogram in six patients. Three patients had premature ventricular contractions which were not suppressed by exercise. Patients presenting with unifocal premature ventricular contractions which were completely suppressible with exercise-that is, benign premature ventricular contractions-were not investigated in this way and are not included here.

\section{METHODS}

The methodology of electrophysiological testing used in our laboratory has been previously described. ${ }^{2}$ In brief, the ventricular stimulation protocol consisted of single and double extrastimuli onto a paced ventricular rhythm and eight beat burst ventricular pacing starting at $300 \mathrm{~ms}$ and decrementing by $20 \mathrm{~ms}$ until 2:1 capture of the ventricle. The protocol was repeated with an isoproterenol infusion (maximum $0.05 \mu \mathrm{g} / \mathrm{kg} / \mathrm{min}$ ) until the end of protocol or reproducible induction of ventricular tachycardia or fibrillation.

The method of obtaining the biopsy sample and its histological characterisation has also been previously described. ${ }^{1}$ Six pieces of myocardium were obtained from the right ventricular apex and septum. All biopsy samples were evaluated independently by two pathologists. Specifically, the examination of the sample included a search for the presence of myocardial necrosis, myocyte degeneration, endothelial swelling, fibrosis, and interstitial oedema as suggested by the Dallas group. ${ }^{3}$ Based on the Dallas group recommendations the biopsy sample was graded as showing myocarditis, borderline myocarditis, or normal. The dominant inflammatory cell population was categorised. The mean inflammatory cell count of 20 high power fields was determined as suggested by Edwards et al. ${ }^{4}$ Repeat biopsy samples were categorised as ongoing, resolving, or resolved myocarditis using the Dallas criteria. $^{3}$

Ventricular tachycardia was diagnosed when three or more ventricular premature contractions occurred in a row. It was further categorised as non-sustained if it lasted less than 30 seconds. It was considered sustained if it lasted for more than 30 seconds or if emergency cardioversion was required.

The immunosuppressive treatment was to give prednisone at a dose of $2 \mathrm{mg} / \mathrm{kg} /$ day for two weeks followed by a gradual tapering over the next four weeks when it was stopped. A reduction in the frequency and duration of ventricular ectopic rhythm (as seen by the total ventricular ectopy count on Holter electrocardiogram) was expected within two to four days of starting steroid treatment. If this was not seen, or if there was any worsening of the ventricular ectopic rhythm, treatment was discontinued.

Patient monitoring at follow up consisted of Holter electrocardiographic recording for the first 48 hours, followed by Holter electrocardiograms taken weekly during the first month, and biweekly outpatient visits.

\section{STATISTICAL METHODS}

Comparisons between values before and after an intervention were performed using the paired $t$ test. Comparisons between groups of patients were performed using a two tailed Fisher's exact test.

\section{Results}

\section{ELECTROCARDIOGRAM AND HOLTER}

ELECTROCARDIOGRAM

Frequent premature ventricular contractions were found either on the standard 12 lead electrocardiogram or the 24 hour Holter electrocardiogram in seven patients. Ventricular tachycardia was found in six patients, being sustained in three and non-sustained in three.

\section{EXERCISE TEST}

Premature ventricular contractions not suppressed by exercise were seen in four patients. Ventricular tachycardia was suppressed with exercise in three patients.

\section{ECHOCARDIOGRAM}

The cardiac structure was normal in all patients. No patient had a reduction of the left ventricular fractional shortening, which 
Table 2 Summary of biopsy findings

\begin{tabular}{|c|c|c|c|c|c|c|c|c|}
\hline $\begin{array}{l}\text { Patient. } \\
\text { No. }\end{array}$ & $\begin{array}{l}\text { Interval } \\
\text { between } \\
\text { biopsies }\end{array}$ & $\begin{array}{l}\text { Myocyte } \\
\text { necrosis }\end{array}$ & $\begin{array}{l}\text { Myocyte } \\
\text { degeneration }\end{array}$ & $\begin{array}{l}\text { Endocardial } \\
\text { cell swelling }\end{array}$ & Fibrosis & Oedema & $\begin{array}{l}\text { Lymphocyte } \\
\text { count }{ }^{\star}\end{array}$ & Diagnosis \\
\hline $\begin{array}{l}1 \\
2 \\
3 \\
3 \mathrm{~b} \\
4 \\
4 \mathrm{~b} \\
5 \\
6 \\
6 \mathrm{~b} \\
7 \\
8 \\
8 \mathrm{~b} \\
9 \\
9 \mathrm{~b} \\
9 \mathrm{c} \\
10\end{array}$ & $\begin{array}{l}\overline{-} \\
\overline{6} \text { weeks } \\
\overline{1} \text { year } \\
- \\
\overline{6} \text { weeks } \\
- \\
6 \text { weeks } \\
\overline{11} \text { weeks } \\
4 \text { weeks } \\
-\end{array}$ & $\begin{array}{l}1, M \\
0 \\
1, M \\
0 \\
2, M \\
0 \\
0 \\
0 \\
0 \\
0 \\
2, M \\
0 \\
1, M \\
0 \\
0 \\
1, M\end{array}$ & $\begin{array}{l}1, M \\
1, M \\
2, M \\
1, F \\
2, M \\
1, M \\
1, M \\
1, M \\
1, F \\
1, M \\
2, M \\
1, M \\
2, M \\
1, M \\
0 \\
1, M\end{array}$ & $\begin{array}{l}1, \mathrm{M} \\
1, \mathrm{~F} \\
2, \mathrm{D} \\
1, \mathrm{~F} \\
2, \mathrm{D} \\
1, \mathrm{M} \\
1, \mathrm{D} \\
2, \mathrm{~F} \\
1, \mathrm{M} \\
1, \mathrm{D} \\
2, \mathrm{D} \\
1, \mathrm{M} \\
1, \mathrm{D} \\
1, \mathrm{D} \\
1, \mathrm{D} \\
1, \mathrm{M}\end{array}$ & $\begin{array}{l}0 \\
1 \\
1 \\
1 \\
1 \\
0 \\
0 \\
1 \\
0 \\
1 \\
0 \\
1 \\
0 \\
1 \\
0 \\
0\end{array}$ & $\begin{array}{l}1 \\
1 \\
1 \\
0 \\
2 \\
1 \\
0 \\
1 \\
1 \\
1 \\
0 \\
1 \\
0 \\
0 \\
0 \\
0\end{array}$ & $\begin{array}{c}10 \cdot 1 \\
5 \cdot 6 \\
9 \cdot 3 \\
4 \cdot 1 \\
12 \cdot 7 \\
6 \\
4 \cdot 4 \\
6 \cdot 4 \\
5 \cdot 1 \\
5 \cdot 8 \\
7 \cdot 8 \\
5 \cdot 7 \\
8 \cdot 4 \\
4 \cdot 4 \\
3 \cdot 4 \\
7 \cdot 8\end{array}$ & $\begin{array}{l}\text { Myocarditis } \\
\text { Borderline } \\
\text { Myocarditis } \\
\text { Resolving } \\
\text { Myocarditis } \\
\text { Resolving } \\
\text { Borderline } \\
\text { Borderline } \\
\text { Borderline } \\
\text { Borderline } \\
\text { Myocarditis } \\
\text { Resolving } \\
\text { Myocarditis } \\
\text { Resolving } \\
\text { Resolving } \\
\text { Borderline }\end{array}$ \\
\hline
\end{tabular}

$0=$ absent; 1 = mild; 2 = moderate; $b=$ biopsy No. $2 ; \mathrm{c}=$ biopsy No. $3 ; \mathrm{D}=$ diffuse; $\mathrm{F}=$ focal; $M=$ multifocal.

${ }^{\star}$ Mean count from 20 high power fields.

ranged from 32 to $49 \%$ on the initial examination (mean (SD) $39(5 \cdot 5))$. Over the follow up period (8-39 months, mean 22 months), this changed to a range (mean (SD)) of $31-51 \%$ (41 (6)), which was not significantly different on a paired $t$ test $(P=0 \cdot 9)$. The left ventricular end diastolic dimension was normalised to the upper limit of normal expected for height, and varied from 87 to $129 \%$ (103 (14)) on the initial study. It changed at follow up to a range of $85-113 \%$ (105 (11)), which was not significantly different $(P=0 \cdot 5)$.

CARDIAC CATHERISATION AND ANGIOGRAPHY All patients were found to have normal haemodynamic catheter findings. There was no angiographic evidence of arrhythmogenic right ventricular dysplasia or any other abnormality in any of the patients.

\section{ELECTROPHYSIOLOGICAL STUDY}

Ventricular arrhythmias could not be induced by programmed stimulation in four patients. In six patients, ventricular tachycardia was induced, which was non-sustained in two and sustained in four patients. In one (patient 10) ventricular tachycardia could only be induced under an infusion of isoproterenol. One patient (patient 1) had a spontaneous appearance of ventricular tachycardia with isoproterenol, although it was not inducible. One patient had inducible ventricular fibrillation and ventricular tachycardia. Supraventricular tachycardias were induced in two patients.
One of these had atrioventricular re-entry tachycardia due to a concealed accessory pathway and the other had atrioventricular nodal reentry tachycardia. These two patients also had inducible atrial flutter.

\section{BIOPSY FINDINGS}

Table 2 summarises the biopsy findings of these patients. Five patients had myocarditis and five had borderline myocarditis. Myocardial necrosis was present in six patients. Myocyte degeneration was found in all, being mild in six and moderate in four patients. Endothelial cell swelling was noted in all, being mild in six and moderate in four patients. Fibrosis was seen in five and intercellular oedema in six. Inflammatory cell infiltration of the myocardium with the dominant cell population being lymphocytes was seen in all patients. The mean lymphocyte count from 20 high power fields ranged from 4.4 to $12 \cdot 7$ (mean $7 \cdot 8$ ). All but one patient (with a count of 4.4 ) had $>5$ cells per high power field. No patient had deposition of immune substances in the myocardium.

\section{OTHER TESTS}

Viral serology for myocarditis viruses was negative in all patients. No connective tissue disorder was found in any patient and immune studies were negative.

MANAGEMENT

Table 3 summarises the details of treatment

Table 3 Treatment and clinical results

\begin{tabular}{|c|c|c|c|c|c|c|c|c|}
\hline $\begin{array}{l}\text { Patient } \\
\text { No. }\end{array}$ & $\begin{array}{l}\text { Steroid } \\
\text { treatment }\end{array}$ & Result & $\begin{array}{l}\text { Holter results } \\
\text { before } \\
\text { treatment } \\
(P V C \%)\end{array}$ & $\begin{array}{l}\text { Holter results } \\
\text { after } \\
\text { treatment } \\
\text { (PVC\%) }\end{array}$ & Resurgence & Azathioprine & $\begin{array}{l}\text { Follow up } \\
\text { (months) }\end{array}$ & Outcome \\
\hline $\begin{array}{r}1 \\
2 \\
3 \\
4 \\
5 \\
6 \\
7 \\
8 \\
9 \\
10\end{array}$ & 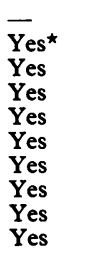 & $\begin{array}{l}\text { NC } \\
\text { NC } \\
\mathbf{R} \\
\mathbf{R} \\
\mathbf{R} \\
\text { Imp } \\
\text { NC } \\
\mathbf{R} \\
\text { Imp } \\
\text { NC }\end{array}$ & $\begin{array}{r}32 \\
34 \\
3 \\
<1 \\
11 \\
37 \\
53 \\
9 \\
18\end{array}$ & $\begin{array}{r}16 \\
55 \\
0 \\
<1 \\
0 \\
3 \\
35 \\
-9 \\
19\end{array}$ & $\begin{array}{l}\overline{-} \\
\text { No } \\
\text { No } \\
\text { No } \\
\text { Yes } \\
\overline{\text { No }} \\
\text { Yes } \\
-\end{array}$ & 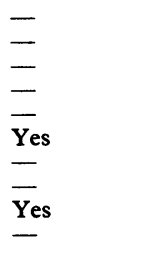 & $\begin{array}{l}21 \\
10 \\
27 \\
38 \\
17 \\
39 \\
23 \\
25 \\
8 \\
9\end{array}$ & $\begin{array}{l}N C \\
N C \\
R \\
R \\
R \\
\text { Imp } \\
N C \\
R \\
\text { Imp } \\
N C\end{array}$ \\
\hline
\end{tabular}

Imp = improved; NC = no change; $R=$ resolved.

^Four days only. 
and clinical results. All patients but one were treated with prednisone. One patient (patient 1) developed chickenpox soon after the biopsy sample was taken and therefore the steroid treatment was not given. He was asymptomatic and had reduction of ectopy on exercise, so a clinical decision was taken not to treat him. He was followed up and remains well, with similar ectopy rates. In one patient steroid treatment was given for four days, but as no response was seen it was discontinued.

Of the eight patients who received steroids for the full course, an improvement in the ventricular ectopy count for each 24 hours was seen on the Holter electrocardiogram during treatment in six patients. This was documented by a reduction of the premature ventricular contraction count on the Holter electrocardiogram by more than $80 \%$. In four patients there was total resolution on the Holter electrocardiogram showing only the occasional premature ventricular contraction.

Two patients had an improvement in, but not a total resolution of, ventricular ectopic rhythm. Patient 6 had a premature ventricular contraction count of $30000 /$ day (37\%) before starting steroid treatment. The number of premature ventricular contractions did not change with the use of flecainide, but decreased to $3000 /$ day (6\%) during steroid treatment. When weaning of the steroids began, the count increased back to $30000 /$ day $(25 \%)$. The dose of prednisone was therefore increased back to $2 \mathrm{mg} / \mathrm{kg}$ /day and azathioprine was added at a dose of $1 \mathrm{mg} / \mathrm{kg} /$ day. Weekly 24 hour Holter monitoring was performed and showed premature ventricular contraction counts between 1000 and $4000 /$ day $(1-2 \%)$. One month later, on attempting to wean the patient from prednisone, the premature ventricular contraction count reverted to $26000 /$ day $(17 \%)$. The prednisone was nevertheless weaned due to the development of unacceptable Cushingoid features and the dose of azathioprine was increased to $1.5 \mathrm{mg} / \mathrm{kg} /$ day. Atenolol was added to the regimen. Azathioprine was given for a total of six months and then stopped. The atenolol was continued. Now, 39 months after presentation, he remains stable with premature ventricular contraction counts around $9000 /$ day (3\%), but at a recent exercise test he had a brief episode of non-sustained ventricular tachycardia.

Patient 9 had 6000 premature ventricular contractions/day (9\%) at presentation, with 50 couplets and five runs of non-sustained ventricular tachycardia on the 24 hour Holter electrocardiogram. With steroids the counts decreased immediately to $0-3$ premature ventricular contractions/day $(<1 \%)$. Two weeks after weaning was started, the counts increased back to 2000 /day (2\%) with one triplet. She returned with a syncopal event and therefore a repeat electrophysiology study was performed and a repeat biopsy sample taken. The electrophysiological study showed inducible non-sustained ventricular tachycardia and the biopsy sample showed a picture of resolving myocarditis. As the patient objected to the acne induced by steroids, they were stopped and azathioprine was given at a dose of $1 \mathrm{mg} / \mathrm{kg} /$ day for three months. Holter 24 hour electrocardiograms performed every two weeks showed premature ventricular contraction counts between 500 and 1000/day (9\%), but no couplets or ventricular tachycardia. At follow up eight months later she remains well and asymptomatic.

In two patients there was no change in the ectopy rate during or after steroid treatment. No patient showed worsening of arrhythmia on starting steroids and none showed progression to a picture of cardiomyopathy at follow up.

Follow up for the whole group ranged from 8 to 39 months (mean 22).

\section{REPEAT BIOPSY SAMPLES}

Table 2 summarises the details of the repeat biopsies. A repeat biopsy was performed four weeks to one year after the first biopsy in five patients. Four patients who had myocarditis at the first biopsy showed resolving myocarditis at the time of the second biopsy. One patient who had had borderline myocarditis on the first occasion continued to show borderline features.

\section{OUTCOME ANALYSIS}

Factors that seemed to differentiate those patients who responded to steroids and those who did not were as follows. The responders were more likely to be symptomatic (six of six) than not (none of two) $(P<0.05)$. Those who responded to steroids (four of six) had an inducibility rate at programmed stimulation compared with those who did not respond to steroids (one of two) ( $P$ value not significant). No histological feature distinguished the two patients who showed no improvement with immunosuppressive treatment from the six who showed an improvement. The two children who did not improve (and the one who received steroids for four days only), however, were asymptomatic at presentation and had ventricular tachycardia which was suppressed by exercise.

Of note is one patient (patient 8) who had a history only of supraventricular tachycardia, but who had atrial and ventricular tachyarrhythmias inducible at the electrophysiology study. Because of the unusual irritability of the heart, a biopsy sample was taken. At the repeat electrophysiology study performed three months after treatment began, only nonsustained ventricular tachycardia could be induced with isoproterenol. The repeat biopsy sample showed resolving myocarditis. Holter monitoring at follow up continues to show no evidence of ventricular arrhythmia.

\section{Discussion}

We found myocarditis or borderline myocarditis on endomyocardial biopsy in 10 of $69(14 \%)$ children with ventricular ectopic rhythm and an apparently normal heart. Eight of these 10 patients were treated with a full course of immunosuppressive drugs, with 
improvement in six patients. Thus our report reiterates the importance of an endomyocardial biopsy in children with ventricular ectopic rhythm. This report also suggests that immunosuppression is useful in the management of children with myocarditis or borderline myocarditis and ventricular ectopic rhythm.

\section{INVASIVE TESTING}

We have found it useful to combine catheterisation, electrophysiological study, and biopsy into a single procedure which provides a thorough evaluation of children with ventricular ectopic rhythm. Patients with unsuspected ventricular arrhythmias have been shown to have subtle abnormalities on cardiac catheterisation. ${ }^{5}$ The usefulness of programmed ventricular stimulation in children with ventricular arrhythmias and an apparently normal heart has also been shown. ${ }^{2}$ We believe that programmed stimulation provides important management information, whatever its result. The inducibility of haemodynamically significant ventricular tachycardia or ventricular fibrillation would prompt a more aggressive approach to management. On the contrary, the lack of inducibility of such serious arrhythmias in an asymptomatic patient would shift us in the direction of expectant management in a patient with a normal biopsy result.

VALUE OF BIOPSY

Previous reports have shown that patients with ventricular arrhythmia and an apparently normal heart may have unsuspected myocarditis. The incidence of such myocarditis has varied from $8 \%$ (one of 12 ) reported by Sugrue et al, ${ }^{6} 9 \%$ (three of 33) in our previous report, ${ }^{1} 17 \%$ (three of 18 ) reported by Strain et $a l,{ }^{7}$ and $50 \%$ (six of 12 ) reported by Vignola et $a .^{8}$ Thus, the endomyocardial biopsy is an important part of the workup of the patient with ventricular ectopic rhythm of unknown cause. Indeed, it would be unsafe to call the heart "normal" until after the biopsy result is available. The importance of the biopsy in the evaluation of the child with ventricular ectopic rhythm cannot be overemphasised. Our report and others have clearly showed that ventricular arrhythmias may be the only sign of a myocardial process that is potentially reversible.

\section{IMMUNOSUPPRESSIVE TREATMENT}

The use of steroids in myocarditis is contentious. Mason et $a l^{9}$ used prednisone and azathioprine in 10 patients with congestive heart failure and myocarditis proved by biopsy, and produced a definite improvement in four. Jones et $a l^{10}$ treated 20 patients with decreased left ventricular function and myocarditis or borderline myocarditis with immunosuppressive drugs. They showed a significant improvement in left ventricular function in those with borderline myocarditis but not in those with myocarditis. Chan et al ${ }^{11}$ treated 13 children with congestive heart failure secondary to myocarditis with immuno- suppression. All the 12 who survived showed significant clinical improvement. Vignola et $a l^{8}$ treated six young adults with myocarditis on biopsy. After immunosuppressive treatment, all showed improvement in their ventricular arrhythmia and resolution of the biopsy findings.

These studies and ours add weight to the use of immunosuppressive treatment in patients with myocarditis and borderline myocarditis whatever their mode of presentation, whether it be with congestive heart failure or with ventricular arrhythmia. All these studies, like ours, suffer from the lack of a control group and the paucity of patient numbers. Therefore the improvement could have been in spite of treatment, particularly as myocarditis can show a spontaneous improvement. ${ }^{12}$ What cannot be explained, however, is the recrudescence of signs and symptoms when the steroids were weaned and their resolution for a second time with the start of azathioprine treatment. This temporal association lends support to the theory that these drugs are indeed responsible for the improvement. Whether it is the anti-inflammatory effects that are responsible for such an improvement remains to be shown. We also feel that empirical treatment with antiinflammatory drugs without a prior biopsy is unjustifiable.

\section{BIOPSY CRITERIA}

According to the Dallas criteria, ${ }^{3}$ the diagnosis of borderline myocarditis is an indication for repeating the biopsy. Our report, and that by Jones et al, ${ }^{10}$ suggest that borderline myocarditis may itself be a finding that merits treatment. In such patients the use of quantitative criteria to judge progression of the disease and its response to treatment becomes relevant. We have used the inflammatory cell count method proposed by Edwards et al. ${ }^{4}$ We feel that the conjoint use of the Dallas criteria along with a quantitative method may help to monitor progress of the disease process in selected patient groups with myocarditis.

\section{OTHER ASPECTS}

An important finding in our study was the relation between the presence of symptoms and the positive response to steroids. In view of the potential seriousness of the problem, however, we continue to thoroughly investigate and treat all children with ventricular ectopic rhythm, whatever their mode of presentation.

\section{Conclusions}

In conclusion, we believe that an endomyocardial biopsy is indicated in all children with ventricular ectopic rhythm and an apparently normal heart once other causes of ventricular arrhythmia have been excluded. We also feel that the use of immunosuppressive drugs adds an important additional tool to the armamentarium of the doctor taking care of children with potentially serious ventricular arrhythmias. 
We thank Dr C L Case for allowing us to report patients in his care.

1 Wiles HB, Gillette PC, Harley RA, Upshur JK Cardiomyopathy and myocarditis in children with venCardiomyopathy and myocarditis in children with ven-
tricular ectopic rhythm. $₹ \mathrm{Am}$ Coll Cardiol 1992;20: tricular

2 Noh CI, Gillette PC, Case CL, Zeigler VL. Clinical and electrophysiological characteristics of ventricular tachycardia in children with normal hearts. Am Heart f 1990; 120:1326-33.

3 Aretz TH, Billingham ME, Edwards WD, et al. Myocarditis. A histopathologic definition and classification. Am ₹ Cardiovasc Pathol 1986;1:3-14.

4 Edwards WD, Holmes DR Jr, Reeder GS. Diagnosis of active lymphocytic myocarditis by endomyocardial biopsy. Quantitative criteria for light microscopy. Mayo Clin Proc 1982;57:419-25.

5 Deal BJ, Miller SM, Scagliotti D, Prechel D, Gallastegui $\mathrm{J}, \mathrm{Hariman}$ RJ. Ventricular tachycardia in a young population without overt heart disease. Circulation 1986; 73:1111-8.

6 Sugrue DD, Holmes DR Jr, Gersh BJ, et al. Cardiac histology findings in patients with life-threatening ventricular arrhythmias of unknown origin. $\mathcal{f}$ Am Coll Cardiol 1984; 4:952-7.

7 Strain JE, Grose RM, Factor SM, Fisher JD. Results of endomyocardial biopsy in patients with spontaneous ventricular tachycardia but without apparent structural heart disease. Circulation 1983;68:1171-81.

8 Vignola PA, Aonuma K, Swaye PS, et al. Lymphocytic myocarditis presenting as unexplained ventricular arrhythmias: diagnosis with endomyocardial biopsy and response to immunosuppression. F Am Coll Cardiol 1984;4:812-9.

9 Mason JW, Billingham ME, Ricci DR. Treatment of acute inflammatory myocarditis assisted by endomyocardial biopsy. Am $千$ Cardiol 1980;45:1037-44

10 Jones SR, Herskowitz A, Hutchins GM, Baughman KL. Effects of immunosuppressive therapy in biopsy-proved myocarditis and borderline myocarditis on left ventricular function. Am f Cardiol 1991;68:370-6.

11 Chan KY, Iwahara M, Benson LN, Wilson GJ, Freedom RM. Immunosuppressive therapy in the management of acute myocarditis in children: a clinical trial. $\Im \mathrm{Am}$ Coll Cardiol 1991;17:458-60.

12. Mason JW, O'Connell JB. Clinical merit of endomyocardial biopsy. Circulation 1989;79:971-9. 